\title{
Organization and Individuals of Nationalism
}

\author{
XU Haiyan \\ Officers college of CAPF, Chengdu, 610213, China
}

\begin{abstract}
In the "imagined community", how to handle the relationship between organizations and individuals in the community, and in particular the rights and obligations of the individual is very important. Nationalism, this premise is a lie huge obstacle in the personal front, whether individuals under the banner of nationalism really be able to find a self-salvation of the road in the game and groups in and whether the rights in the group truly balanced self and obligations, which are under the banner of nationalism which face one pair of our contemporary problems to be solved nationalism and exploring.
\end{abstract}

Keyword-Nationalism, organization, individual

\section{民族主义下的团体和个人}

徐海艳

武警警官学院，四川，成都 610213

摘 要 在“想象的共同体”中, 如何处理好共同体中团体和个人的关系, 又特别是个人的权利和义务问题显得尤为重要。民族主义 这个前提又是一个横亘在个人面前的巨大障碍, 在民族主义的旗帜下的个人是否真能在与团体的博栾中找到一条自我救赎之路, 以及 是否能在团体中真正的平衡自我的权利和义务关系, 这都是民族主义这面大旗下一个对我们当代的民族主义问题亟待解决和探讨的问 题。

关键词 民族主义，团体，个人

在 “想象的共同体” 中, 如何处理好共同体中团体和 个人的关系, 又特别是个人的权利和义务问题显得尤为重 要。民族主义这个前提又是一个横亘在个人面前的巨大障 碍，在民族主义的旗帜下的个人是否真能在与团体的博亦 中找到一条自我救赎之路, 以及是否能在团体中真正的平 衡自我的权利和义务关系, 这都是民族主义这面大旗下一 个亟待解决和探讨的问题。民族主义的根本属性是要求重 视团体而其实个人的, 甚至是提倡牺牲个人以保全团体的。 安德森曾写到 “没有什么比无名战士的纪念碑和墓园, 更 鲜明地表现现代民族主义文化了” ${ }^{[1]}$ 不难看出, 这里所体现 出的民族主义精神实质下的个人想象只有在实际生活取舍 中幻化为真实的团体性存在, 个人价值的认同和取向标尺 只有在向团体利益不断的靠拢时, 民族主义的无尚号召力 和凝聚力才能得到了淋漓尽致的表现。“你只要想象一下 一般民众对于好事者宣称发现某个无名战士的名字, 或是 坚持必须在碑中存放一些真正的遗骨时的反应, 就可以感 受到此事的现代性了” ${ }^{[2]}$ 。民族主义是一个与时俱进的, 具 有明确现代性的价值观, 要在民族主义的范围内去构建团
体与个人的关系准则就必须要去克服这种民众的偏狭心 态, 树立持中的意识; 同时, 在这个准则的过程中我们在 崇尚集体优先主义传统的中国, 在高高飘扬的民族主义旗 帜上要去镌刻出个人的权利绣章是顺应了发展呢, 还是忤 逆了传统? 我们在面对民族主义的集体主义价值取向时, 它是否还具有整合团体和个人的功用呢? 如果我们遵从民 族主义对个人能够加以打压和限制的内在逻辑, 那么个体 性格的彰显机制又该如何建立呢? 接下, 试将从这几个问 题加以分析。

\section{1. 抛掉偏狭心态, 应平和、持中的应对}

“民族主义”一语词本身就深刻的包含了两种可能性的 倾向。既有可能表现为偏执狭险的民族主义, 又可能处理 得当在求同存异的氛围中持中平稳的泰然处之。不过在日 益多元化的二十一世纪, 这种对待民族主义的态度仅为手 段的分殊, 问题的实质在于我们倡导民族主义作为一种意 识形态所倡导和张扬的目的何在? 显然此时民族主义所采 取的手段亦显得十分重要。 
世界历史上两次世界大战的硝烟里到处都弥漫着偏狭 的民族主义气息, 在消散之后又深刻的警示我们民族主义 并非仅存在与意识之中, 它既可以导致民族独立的荣光, 也可能是民族灭绝的悲戚。显然降低为手段化的民族主义 是值得我们加以鞭答的。在 “共同体” 的想象中虚骄、偏 狭、狂狷之气必定要加以遏制。二战中, 希特勒的纳粹主 义就是在 “民族主义” 和 “社会主义” 的口号下屠杀了上 百万的犹太人和波兰人。现在当我们沉浸于《辛德勒的名 单》的悲愤中时, 实际上这又是一轮新的逆希特勒民族主 义的 “民族主义” 的升温。大众媒体的渲染和宣传所带来 的强烈价值判断倾向和现实个体情感的某种 “缺口”一接 合, 新的偏狭便应时而生。

在中国从 1998 年驻贝尔格莱德大使馆被炸, 1999 年的 钓鱼岛事件和 2001 年的 “九一一” 事件所引发的在上海、 成都等大城市的群众性抗议行为中也不难看到民族主义的 伟力所在, 其背后所投射出的内在实质又不仅在爱国主义 和反抗精神的喷射, 而且也彰显了在中国民族主义又一轮 升温的过程中, 偏狭和暴烈之气所夹杂的经历了长期被压 抑后的民族精神新的搏动。在此, 我们切要注意中国的民 族主义沦落为偏狭的工具和手段。

实际上, 在民族主义是否存在工具性的鉴别过程中, 我们不难发现一些学者所谓的在中国这样一个后发的现代 化国家, 用民族主义来凝聚内部力量, 抵抗资本主义的全 球霸权具有正当性。当然这不无道理。且可堂而皇之的成 为反西方世界对中国进行打压和意识形态渗透的有力武器 和论据。但实际上如果把这种正当性不恰当的作为了工具 性的手段使用, 那么这一民族主义也就未必就有有效性, 这种偏狭的态度只可能把民族主义带上极端, 目中无人, 夜郎自大, 甚至重蹈 “天朝上国” 的迷梦。

我们真正应构建的是把民族主义作为一种精神支撑和 民族国家内在的传统品质, 赋予其中华千年文明所特有的 博大胸怀和宽容气质。在世界潮流的涤荡和竞争中适度、 持中的保持开放的气度和 “求同存异” 的宽阔眼界, 切莫 小家子气走向利已主义的自私自利的深渊。可喜的是, 现 今的中国在取得巨大进步时仍然以低姿态和学习的精神去 融入世界。不管是 “和平崛起” 还是 “中国威胁论” , 在 民族主义的洪潮中我们是可以找到归宿和支撑的。民族主 义旗帜的高扬, 必将插在中国深重厚实的土壤之上, 才能 迎风招展。

这种胸怀和气质, 正是我们避免先天不足的民族主义 走上歧路, 引导它不断适应全球化趋势的题中之意, 只有 这样才能把民族主义塑造成构建我们和谐社会的强大精神 支撑。

\section{2. 民族主义的旗帜上能镌刻出个人权利的绣章吗?}

民族主义这一面旗帜就如下里巴人的通俗曲目一样附 和者甚众。虽然民族主义在本质上是要求保全团体, 轻视 甚至牺牲个人的, 但是民族主义同时也还有一个保全团体 中个人权利的倾向。它强调个人服务或者服从于团体的根 本动机在于个人是在团体中去寻求自我保护的避难所。所 以既然团体在为个人提供庇护, 而且个人对团体有着某种 天然的联系而非强迫的加入团体的话, 那么团体对个人的 予取予求在某种程度上说也是有理可循的。如果自披上民 族主义的外衣, 则更显得有理有据了, 显然这里民族主义 的外在包装为集体主义的宣扬和对个人权利的䅐视提供了 一个更为隐蔽的场所。

不过从我国改革开放的这几十年来看, 所谓民族主义 的回潮甚至滥解的却存在如上所分析的不合理成分。但是 去掉狂狷和虚骄之气后, 民族主义的这种集体整合力所带 来的认同感和价值取向终归成绩卓然, 而且仍将继续发挥 其巨大的凝聚力和整合力作用。相应的个体性格也得到了 十足的张扬。单调的粗布衣服和绿军装早就被七彩服饰排 挤到了历史的垃圾堆里面了, 涂鸦墙、酒吧、街舞……这 些都在纷异的生活元素中呈现出全新的个性化体现。可见 在改革开放过程中，民族主义力量彰显下的团体与个人的 兼容调和的暗流汹涌, 一则使民族主义得到了更大的认可 度, 一则又为个体性格的发挥提供了一个宽广的舞台。似 乎表明了民族主义正在努力的一个方向就是要把这个民族 可避免的痛苦减少到最低程度, 显然即使这样我们也不能 忽视团体中个性要求得到彰显的呼唤。

可要在民族主义的大旗上镌刻个人权利的绣章就是要 在持中的心态中整合团体与个人间的利害冲突。民族主义 本性是要求个人服务于或服从于团体的, 可是这种要求的 前提是在于团体能够为个人提供 “庇护所”。一旦这个前 提被推翻掉, 其实个人对个性张扬的强烈欲求是完全可以 挖掘掉民族主义的根基的。不过这种掘墓人的角色扮演亟 待于个性得到彰显的机制的建立，否则在缺少这种机制作 为保障的情况下, 个体始终都只会蜷缩于团体的巨大威力 下。姑且不论这种机制在民族主义的价值取向下如何建立 的问题，其关键还在于这种机制有无建立的可能性问题更 应被提出来加以讨论。当然。这里就涉及到整个体性格与 民族主义本质上的集体主义诉求二者间是否能够兼容。前 文我们的讨论已经表明只要我们的民族主义能够平和持 中, 那么这种可能性就是存在的。这要求我们必须注意这 样一个深刻的关于权利与义务的对话机制问题，团体与个 人的权利、义务应如何配制, 在民族主义旗帜下则表现为: 团体所承担的权利和义务是不对等的, 它越过了权利和义 务的守恒原则和零界点, 相应团体所多出的这部分权利以 
及因享有权利而转驾出的相应义务则必须要个人去承担, 这同时又表明个人权利在民族主义的旗帜下被损害。如果 这是民族主义的题中之义的话，那么这个被压抑角色的个 人是否会有弹簧效应呢? 在极度被压缩的状况下, 要么个 人完全成为团体的奴役, 要么个人绝地反抗。同时, 是否 可以得出这样的结论, 个人主义势必会推到民族主义的旗 帜, 民族主义所具有的某种先天遗传性, 只适合于父辈或 传播媒介所做出的应民族主义之意而加以自我内化。所以 在民族主义下，个人与团体的权利和义务问题就是民族主 义的一个最基本的立足点, 二者关系调整的好坏直接关系 到我们所要树立的民族主义这一新的意识形态的的建立。

\section{参考文献(References)}

[1] (1)(2)Anderson"Imagined communities: origins of nationalism and walk", Shanghai people's Publishing House

[2] "Sichuan University" 2005

[3] Li Chia Chung "Diplomatic career" fragment recall "hundred year tide" In 201202 period

[4] Li Zhan "The Transformation of Modern European Nationalism and the Rise of "Stress Nationalism" in Asia Africa and Latin America" "Suzhou University" 2009 